\title{
The Effect of Particulate Debris on the Insulation Integrity of SSC Coils During Molding and Collaring
}

E. Nehrlich, F. Markley, and D. Rogers

Fermi National Accelerator Laboratory

P.O. Box 500, Batavia, Illinois 60510

March 1991

* Presented at the Third Annual International Industrial Symposium on the Super Collider [IISSC], Atlanta, Georgia, March 13-15, 1991. 


\section{Disclaimer}

This report was prepared as an account of work sponsored by an agency of the United States Government. Neither the United States Government nor any agency thereof, nor any of their employees, makes any warranty, express or implied, or assumes any legal liability or responsibility for the accuracy, completeness, or usefullness of any information, apparatus, product, or process disclosed, or represents that its use would not infringe privately owned rights. Reference herein to any specific commercial product, process, or service by trade name, trademark, manufacturer, or otherwise, does not necessarily constitute or imply its endorsement, recommendation, or favoring by the United States Government or any agency thereof. The views and opinions of authors expressed herein do not necessarily state or reflect those of the United States Government or any agency thereof. 


\title{
THE EFFECT OF PARTICULATE DEBRIS ON THE INSULATION INTEGRITY OF SSC COILS DURING MOLDING AND COLLARING
}

\author{
E. Nehrlich, F. Markley and D. Rogers \\ Fermilab National Accelerator Laboratory \\ Box 500 \\ Batavia, IL 60510
}

\begin{abstract}
In order to simulate the effect of accidentally introduced debris on SSC coil insulation integrity, models consisting of two pieces of insulated SSC cable have been loaded in an hydraulic press after introducing foreign particles between the layers. The tests were originally suggested by R. Palmer of the SSC Laboratory. A high voltage $(2 \mathrm{Kv})$ was continually applied between the two cables and the load gradually increased until an electrical short occurred. The high voltage was used as an easy method of detecting insulation punctures and to continue the general type of testing begun at Brookhaven by J. Skaritka, now at the SSC Laboratory, and continued at Fermilab by F. Markley and presented at last year's session of the Conference. A range of particles of different size, shape, and hardness were used, and both conducting and insulating particles were included. Fine wires were also used.
\end{abstract}

When the data are normalized using the control (no particles added), data for each cable batch used, there is a slight correlation between pressure at breakdown and particle size for cables insulated with Kapton only. Adjustment must be made for soft particles that tend to deform and for particles with aspect ratios greater than one. Additional measurements have also been made where the epoxy-fiberglass layer was added to the Kapton insulation overwrap. These show a correlation between conductivity and breakdown pressure.

\section{INTRODUCTION}

The magnetic coils of the SSC guide the particles under study around the collider ring. These coils are built with extreme precision, and are placed under great pressure in the collaring and molding process, which may allow foreign particles to compromise the integrity of the coils' insulation. Although the manufacturing area should be kept fairly clean, no study has been done as to how severely dust and related debris can actually affect the insulation of the SSC coils. One way in which such particles could definitely affect the coil's performance is if dust got between layers of the coil and cut through the insulation, causing electrical breakdown. However, nothing was known as to what sizes of contaminants would cause such breakdown. To this end, an array of powders were acquired and then tested between 2 layers of SSC insulated cable to determine the effect of contaminants under pressure. 
Since the point of this investigation was to determine what kind of debris could affect the insulation, we first considered the different characteristics of the possible contaminants. We decided that the three most important variables were size, shape and possibly the conductivity of the contaminant. Two of these factors have obvious effects upon the insulation. The larger a particle is, the more likely it is that it will cut through the insulation and cause electrical breakdown. Also, if a particle is sharp and jagged-edged, it can easily start a tear in the Kapton insulation, and due to the poor tear resistance of Kapton, the tear might propagate. The interesting factor was that of conductivity. We thought that conductivity would not have an effect, because of the high test voltage we were using. If a conductive particle cuts completely through the insulation it will then form a short, and if an insulative particle cuts through, then since it will have torn a hole in the insulation the air around it at $30 \mathrm{~V} /$ mil breakdown strength will not hold off the $2 \mathrm{Kv}$ test voltage, and a short will happen anyway. With Kapton's low tear resistance in mind, we expected a downward sloping curve, when we plotted the results of our tests on a graph of electrical breakdown pressure vs. diameter of particle, with conductive and nonconductive particles being the same, and sharp jagged particles being below the line.

\section{EXPERIMENTAL DETAILS AND SAMPLE PREPARATION}

There were three parts to this investigation. The first part was examining the resistance of Kapton alone, without the surrounding epoxy fiberglass. For the first part, we used the regular Kapton which is currently being used under the epoxy fiberglass in SSC coil. For the second part a special DuPont Kapton coated with a polyimide adhesive was used. It is identified as Kapton CI. The Kapton CI was used in order to compare the all polyimide system with the standard system. The all polyimide system consists of two layers of adhesive coated Kapton each applied half lapped. For this test the adhesive was not fused. The Kapton CI was supplied by Brookhaven National Laboratory. The third part examined the resistance of the complete standard system with both Kapton and epoxyfiberglass insulation, however the epoxy-fiberglass was not cured. The process used for testing was the same in all cases. SSC cable with the insulation under study was combined into test samples consisting of two pieces of cable on top of each other thin edge to thick edge. The powder under study was placed between the pieces of coil with a brush to obtain a smooth even covering of the surface of the coil. Pressure was then placed on these samples with a hydraulic press, made by Dake Corporation. While increasing pressure was brought to bear on the sample, the experimenter tested for electrical insulation breakdown using a high voltage supply, made by Associated Research Inc., and testing for current flow between the two samples. The pressure was increased in 1000 pound increments until current was registered on the meter. The pressures thus found were then graphed with Symphony and Quattro.

We were forced to use cable from several different reels in order to get enough samples. To normalize these, we used the control samples to find the difference in the pressure to breakdown for each cable reel compared to the highest and then added the difference to all the results from that reel. We believe that such differences in pressure to break down were due to the different sized flat areas on top of the cable strands. In fact, one of us (Finley Markley) had already done actual measurements of the flat area and had shown that the difference in flat area accounted for a difference in pressure to breakdown. Figure 1 shows measured control values for the cable reels used.

It should be noted that the total insulation thickness was much less for the Kapton only case than for the other two which were nearly the same thickness in a compressed condition. We included a wide variety of contaminants in this investigation. We also tested conductive particles $(\mathrm{Ni}, \mathrm{Fe}, \mathrm{Al}, \mathrm{SiC}$, etc.) vs. non-conductive particles (silica, $\mathrm{Al}_{2} \mathrm{O}_{3}$, etc.) Furthermore, we included several Airbrasive powders which were made for cutting, to examine the effect of shape. 


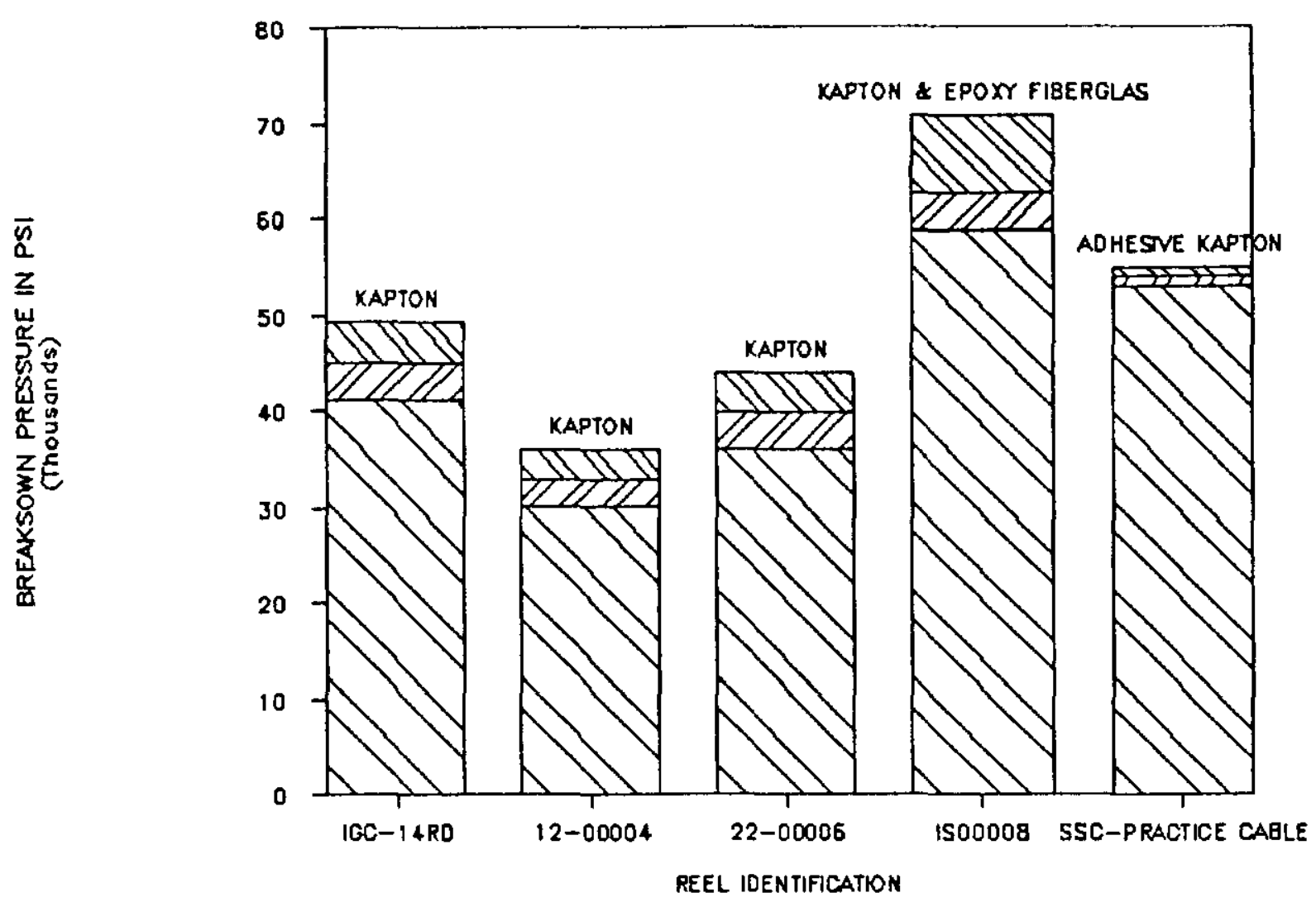

Figure 1. Cable control tests HV insulation breadown

\section{RESULTS}

The majority of the data is presented in figures 2 through 7. The first phase of the investigation on regular Kapton is summarized in figures 2 and 3 with a range of one standard deviation around each point. Figure 2 is non-conductive and figure 3 is conductive. Figures 4 and 5 show the results of the tests with the Kapton CI. Figure 4 is nonconductive and figure 5 is conductive. The tests with both Kapton and epoxy-fiberglass are summarized in figures 6 and 7. Figure 6 is non-conductive and figure 7 is conductive.

\section{INTERPRETATION}

As can be seen from figures 2 and 3 , the conductivity of a particle does not appear to have much effect on electrical breakdown pressure when Kapton only is used as insulation, at least for smaller particles. Figure 4 and 5 show the same thing for Kapton CI and a large range of particle sizes. However, we observed a great difference between conductive and non-conductive particles in our tests of the Kapton and epoxy-fiberglass insulation. As can be seen from figure 7, the conductive particles show a marked decrease in breakdown pressure with size, whereas the non-conductive particles in figure 6 show no decrease with size until the particle reaches a diameter greater than the thickness of the insulation. We eliminated other possible variables when we checked that the particles involved in this test were of the same size, and of the same shape. This behavior is not yet understood. The size of the particle did not have as much effect on breakdown pressure as expected. In figure 2, a downward trend can be seen with greater size, yet the same data could be interpreted as a straight horizontal line within tolerance of the standard deviations. Figure 3, 4, and 5 show very little variance with size, if any. Figure 7, as discussed above, demonstrates a great decrease with size among the conductive particles, even though figure 6 shows no decrease at all among the non-conductive particles. 


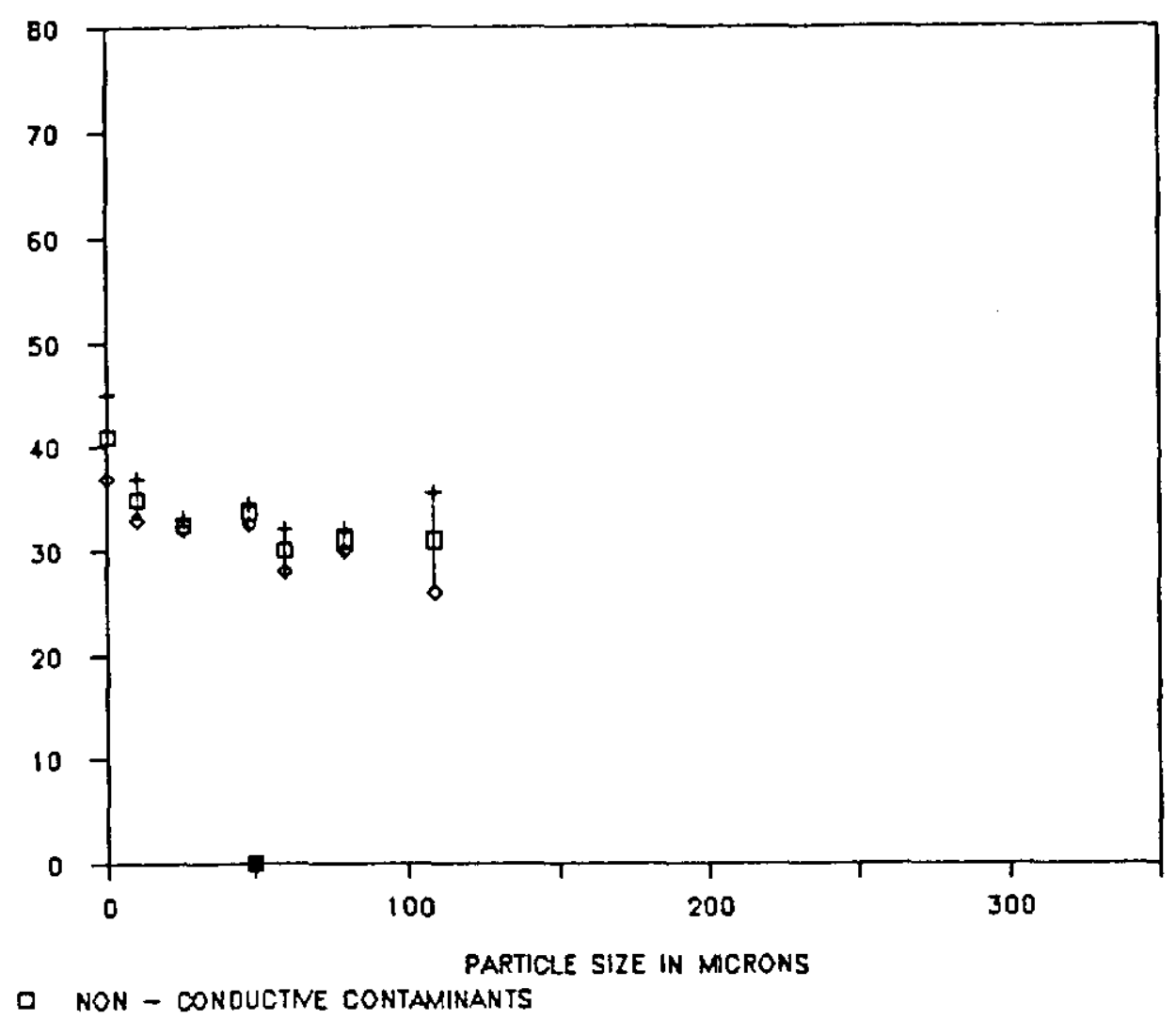

Figure 2. Kapton HV insulation breakdown tests
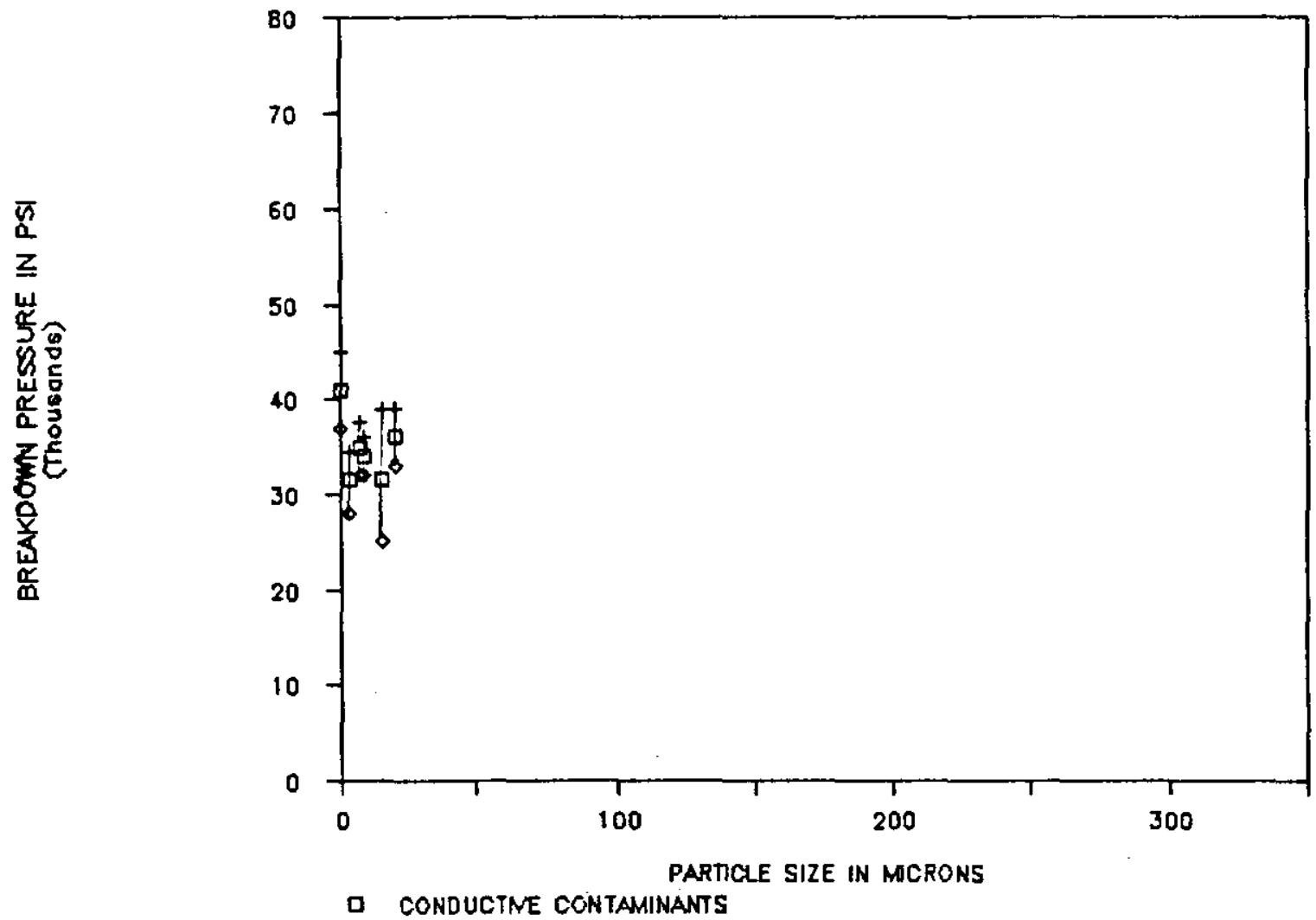

Figure 3. Kapton HV insulation breakdown tests 


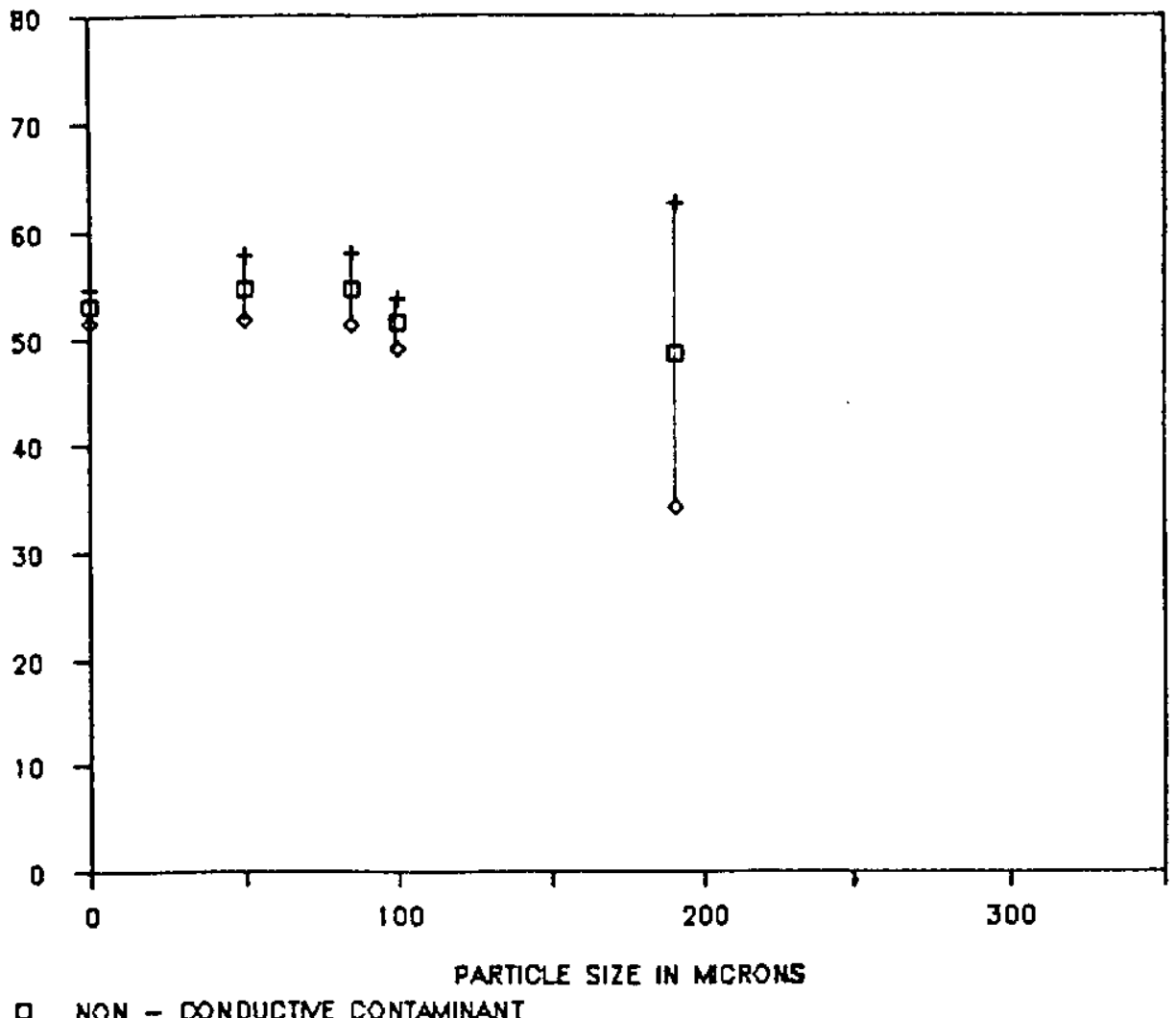

Figure 4. Kapton CI HV insulation breakdown tests

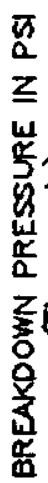

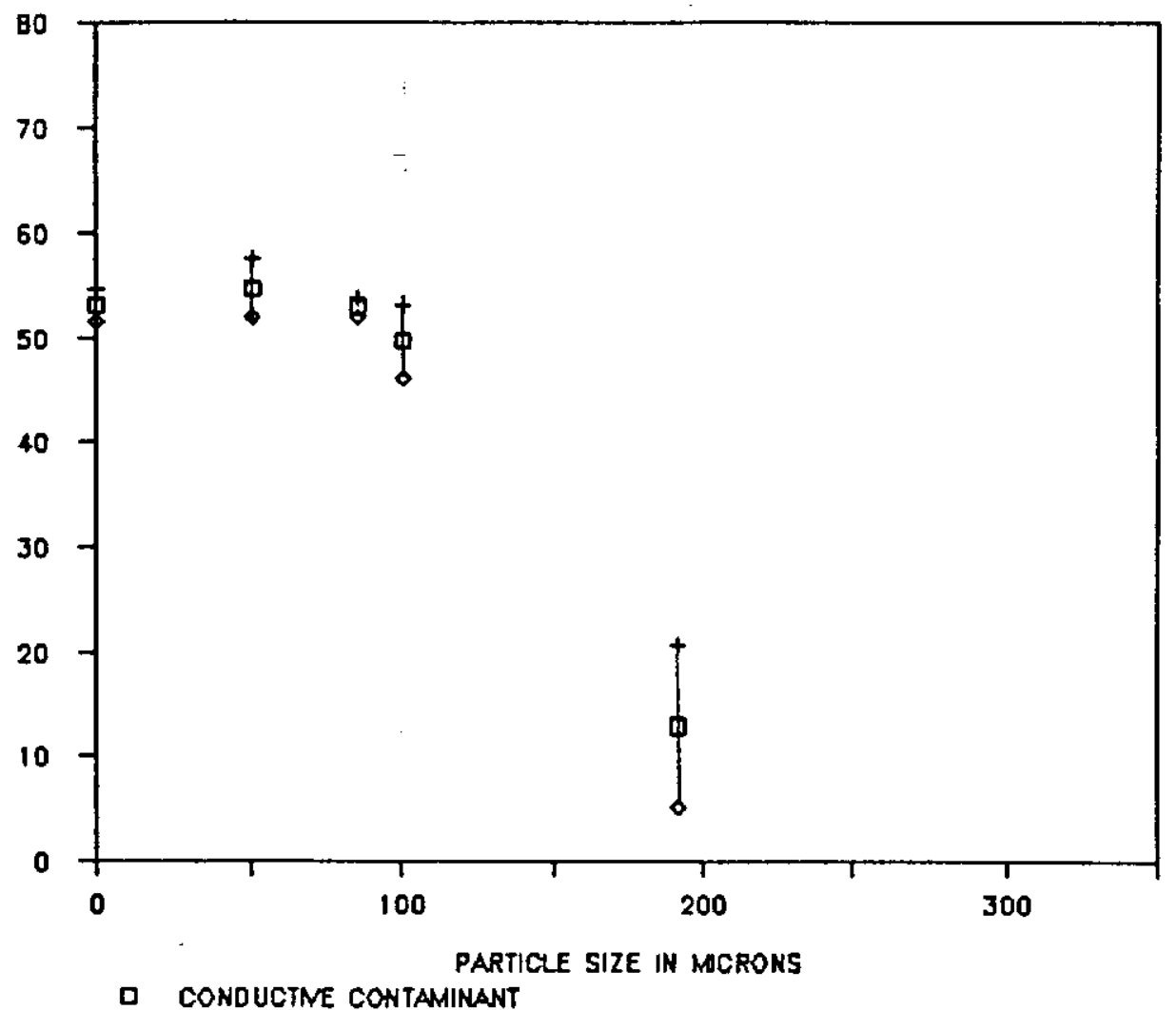

Figure 5. Kapton CI HV insulation breadown tests 


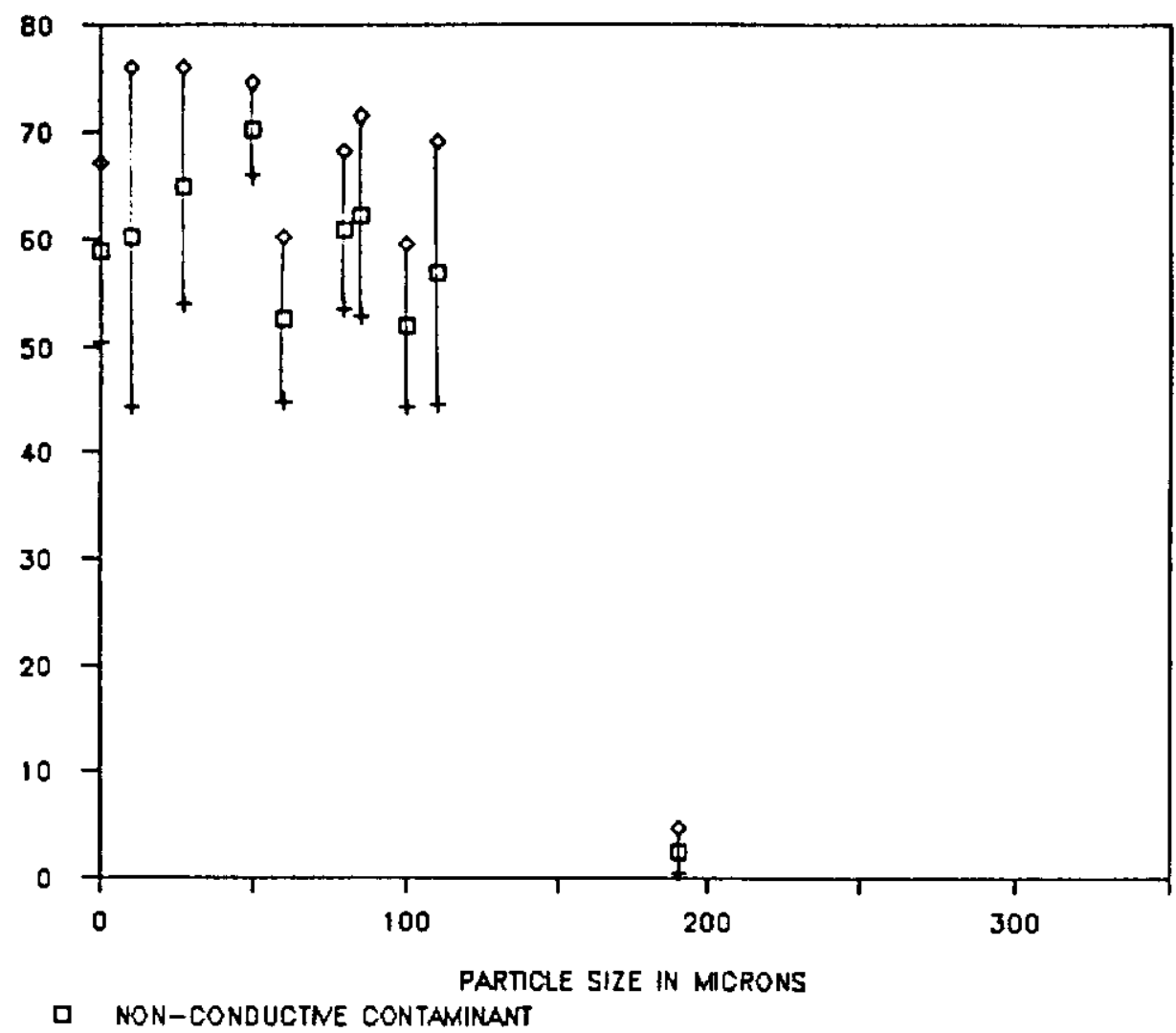

Figure 6. Kapton / Epoxy fiberglass $\mathrm{HV}$ insulation breakdown tests

高

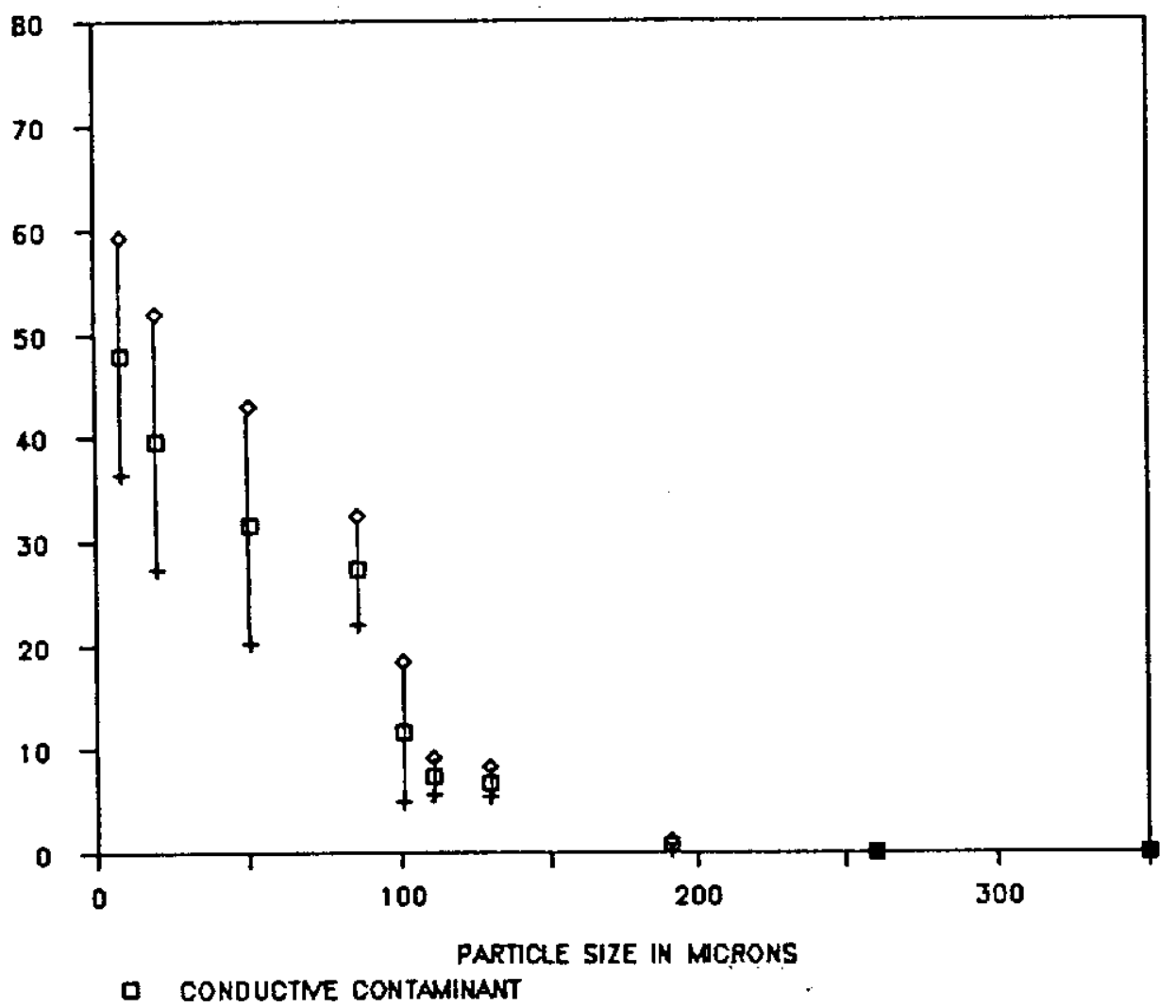

Figure 7. Kapton / Epoxy fiberglass HV insulation breakdown tests 
The shape of the particle was found to have a large effect on breakdown pressure in the case of Kapton only insulation. Such an effect is observed in figure 2, where an Airbrasive powder broke down almost immediately upon testing, due to the fact that their shapes were long and jagged. Upon examination under the microscope, the powders were found to range in length up to 150 microns despite being only $\mathbf{4 0}$ microns in width. The particles were labelled as 50 microns by the manufacturer, probably upon sifting through a 50 micron mesh. However, the shape of the particle did not seem to have any effect in figures $4,5,6$, and 7 since in all of these graphs, a large portion of the powders tested were of the same shape as the Airbrasive powders.

\section{CONCLUSION}

With respect to the three factors assumed to have an effect on break down pressure, size, shape, and conductivity, it was found that their relative importance depended strongly upon the type of insulation being used. The Kapton only insulation showed a very strong sensitivity to the shape of the contaminant, as evidenced by the airbrasive powders used, a very minor decline with size, and no relation to conductivity. How ever, the Kapton plus epoxy-fiber glass insulation had little or no sensitivity to shape and a very strong dependence on size, for conductive particles only.

\section{REFERENCES}

1. Markley, F.W., and Kerby, J.S., "Investigation of the Mechanical Properties of Superconducting Coils", Super Collider 2. Vol. 2, Plenum Press, New York, 1990, pp. $753-763$. 
Appendix 1

Types of contaminants used in order of size

Diameter(microns) I Diameter(mils) I Types of powder

\begin{tabular}{l|c|l}
\hline 23 & 0.12 & Nickei \\
$6-9$ & $0.24-0.35$ & Iron \\
$6-10$ & $0.24-0.39$ & Silver-Coated Nickel \\
10 & 0.39 & Type 5 Airbrasive \\
15 & 0.59 & Tungsten wire \\
20 & 0.79 & Aluminum \\
27 & 1.06 & Type 1 Airbrasive \\
48 & 1.89 & Mesh 325 \\
50 & 1.97 & Type 3,8 Airbrasive \\
60 & 236 & Mesh 260 \\
80 & 3.15 & Mesh 200 \\
85 & 3.35 & Mesh 180 \\
100 & 3.94 & Copper Wire \\
100 & 3.94 & Mesh 150 \\
110 & 433 & Mesh 140 \\
115 & 4.53 & Mesh 120 \\
130 & 5.12 & Mesh 100 \\
190 & 7.48 & Mesh 80 \\
260 & 1024 & Mesh 60 \\
350 & 13.78 & Mesh 50
\end{tabular}

Mesh 140,200,260,325 are silica powders Types 1,3,5 Airbrasives and Meshes $80,150,180$ are Aluminum Oxide powders Type 8 Airbrasive and Meshes 50,60,80,100,120,150,180 are Silicon Carbide powders. (There were two types of Mesh $80,150,180$ ) 